\title{
State of the Art
}

\section{Apoptosis and Cell Homeostasis in Chronic Obstructive Pulmonary Disease}

\author{
Peter M. Henson, Gregory P. Cosgrove, and R. William Vandivier \\ Division of Cell Biology, Department of Pediatrics, and Pulmonary Division, Department of Medicine, National Jewish Medical and Research \\ Center; and COPD Center, Division of Pulmonary Sciences and Critical Care Medicine, Department of Medicine, University of Colorado \\ Health Sciences Center, Denver, Colorado
}

Examination of lung tissue from patients with chronic obstructive pulmonary disease (COPD) reveals the presence of apoptotic cells (1-3). This raises two key questions: What induces the apoptosis and how important is it for pathogenesis of the disease? However, before considering these questions, it is important to emphasize that the Kasahara and colleagues' study (1) used a variety of approaches to show that the cells they were identifying had indeed undergone the process of apoptosis. This does not exclude additional ongoing direct cell damage and necrosis, or postapoptotic necrosis, but does focus attention specifically on apoptosis and its consequences. As noted below, in normal circumstances, apoptotic cells are rapidly removed in situ with minimal local tissue response, a process with a time frame of minutes, not hours, days, or years. Accordingly, the consistent presence of apoptotic cells either means constant induction of apoptosis on a very wide scale or, more likely, defective clearance mechanisms. This then leads us to the third series of questions focusing on the nature of the defective clearance as well as its own contribution to pathogenesis.

Normally, apoptotic cells are rapidly removed from tissues as a component of cellular homeostasis. In fact, programmed cell death (whether of apoptotic or autophagocytic origins) may be considered primarily as a mechanism for cell removal, with an emphasis on removal. We have suggested that this clearance process is normally so efficient that the finding of detectable apoptotic cells in a tissue could reasonably raise the possibility of defects in the clearance mechanisms $(4,5)$ (see below). A striking experiment that supports this contention is that induction of total apoptosis of murine thymocytes results in essentially invisible removal unless the mice are defective in one or more apoptotic clearance systems (6). In humans, clearance of apoptotic neutrophils during acute community-acquired pneumonia is almost invisible $(<1 \%$ detectable apoptosis [7]) compared with cystic fibrosis where we showed evidence of defective clearance (8). Defective clearance may be implicated in lesions of atherosclerosis where statin treatment led to deceased presence of apoptotic cells (9).

Apoptotic cell removal occurs by a unique form of phagocytosis (termed "efferocytosis") $(10,11)$, which can be carried out

(Received in original form March 17, 2006; accepted in final form April 12, 2006) Supported by an Atorvastatin Research Award to R.W.V. sponsored by Pfizer, Inc., and by NIH grants to P.M.H. (HL068864, HL067671, and GM061031) and R.W.V. (HL072018).

Correspondence and requests for reprints should be addressed to Peter M. Henson, Ph.D., National Jewish Medical and Research Center, 1400 Jackson Street, Denver CO 80206. E-mail: hensonp@njc.org

Proc Am Thorac Soc Vol 3. pp 512-518, 2006

DOI: $10.1513 /$ pats.200603-072MS

Internet address: www.atsjournals.org by structural tissue cells, such as fibroblasts, epithelial cells, and endothelial cells, as well as by professional phagocytes, such as macrophages and dendritic cells. However, as noted below, this ingestion of apoptotic cells is only one manifestation of their recognition by surrounding cells, which also includes generation of antiinflammatory mediators, antiproteases, and growth/maintenance factors (Figure 1). These last, we suggest, contribute to replacement of the damaged cells and to the return of normal tissue structure and function (i.e., maintenance of homeostasis). These concepts have set the stage for the hypothesis to be discussed herein, namely that, in COPD, defects in maintenance of cellular homeostasis and of normal responses to apoptosis or damaged cells lead to loss of alveolar structure and of total alveolar numbers (i.e., emphysema; Figure 1).

\section{CELL TURNOVER IN THE ALVEOLAR WALL}

It has been suggested that most of our cells will undergo death and replacement, although rates differ from cell to cell and tissue to tissue (for example, see Reference 12). At one end of the spectrum, approximately $2 \times 10^{11}$ neutrophils and comparably large numbers of erythrocytes and other blood cells are cleared (and replaced) on a daily basis. This turnover is essentially invisible. On the other hand, examination of the normal lung does not usually reveal significant numbers of apoptotic cells. This is presumably because of the following: (1) death is on a cell-bycell basis rather than synchronous, (2) removal is fast and highly efficient, and (3) death and removal are silent (i.e., do not provoke any local response). Blood cells have an inbuilt life span, although the mechanisms underlying this are not fully understood. Intestinal epithelial cells may be similarly controlled. Cells of the alveolar wall may or may not have finite life spans, but, we suspect, are more likely to respond stochastically to casual injurious stimuli-they are, after all, exposed to the external environment, such as skin and gastrointestinal and mucosal surfaces. Thus, evidence of cell death and replication in the noninjured adult human alveolus has been limited (see Reference 1 and Figure 2). Even in experimental animals, the data are far from extensive. Nevertheless, on theoretical grounds as well as from what data are available, we suggest that cell turnover is a key mechanism for maintenance of normal structure here as elsewhere in the body, and indeed, throughout biology.

Defective homeostasis - too much cell death and/or inappropriate replacement-would be expected to lead to disruption of alveolar structures, such as that seen in emphysema. This concept does not exclude the long-standing protease hypothesis but could complement it. Proteolytic effects on basement membrane or alveolar cells likely contribute to apoptosis itself, or as always, to matrix alterations that prevent cell replacement and repair. In addition, a defective response to apoptotic cells itself may, in fact, contribute to the protease-antiprotease balance (13). This may be additionally important in explaining the question of 


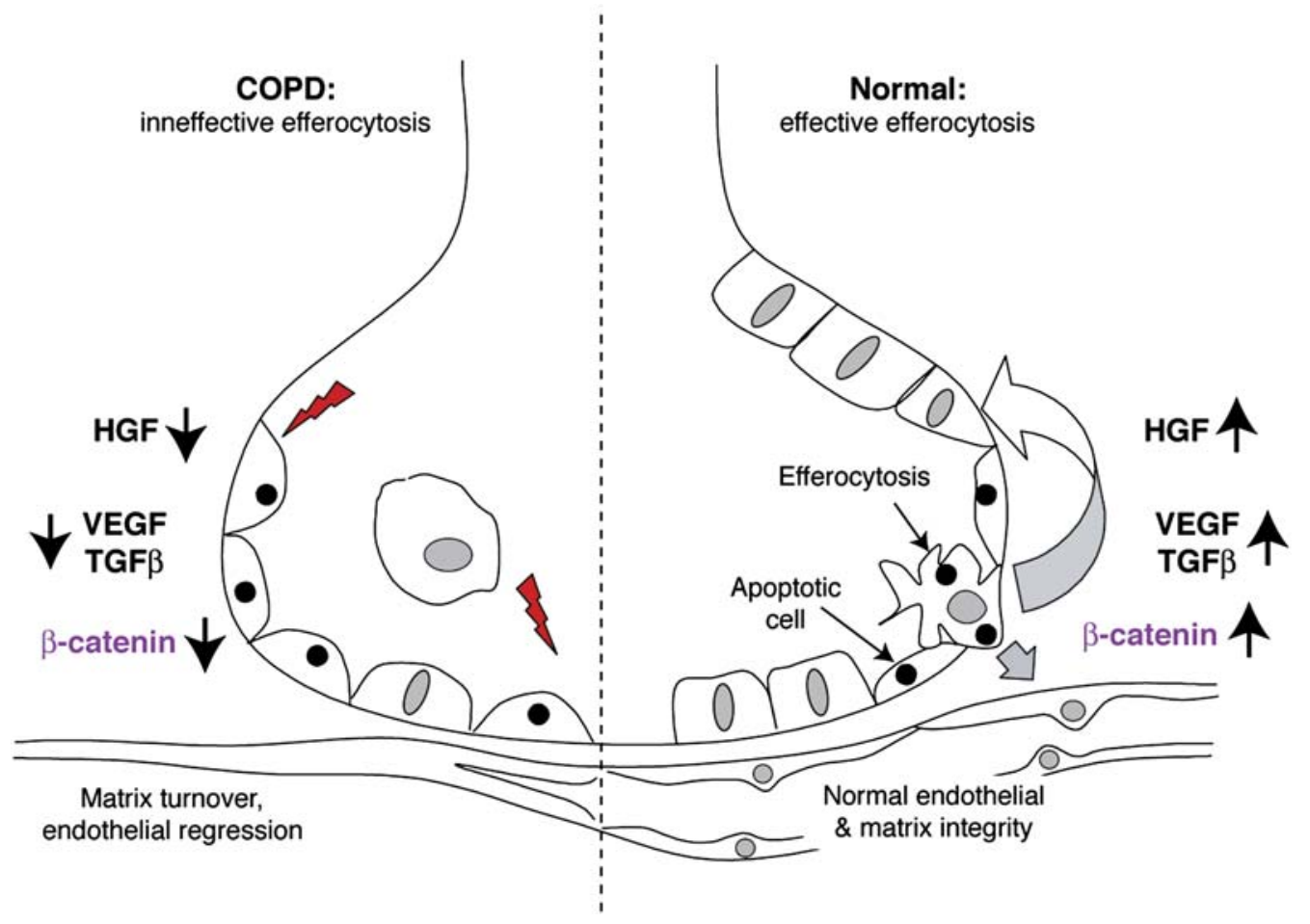

Figure 1. Model for the normal response to apoptotic cells in the alveolus compared to an impaired response proposed for chronic obstructive pulmonary disease (COPD). HGF = hepatocyte growth factor; TGF- $\beta=$ transforming growth factor $\beta$; VEGF = vascular endothelial growth factor.

persisting inflammation after smoking cessation-a significant issue in COPD (14). It seems likely that there is substantial cross-talk between alveolar epithelial and endothelial cells, such that overwhelming loss of either may cause death of the other, even if repair mechanisms are intact. In contrast, when repair mechanisms are impaired, cell death may result in loss of alveoli and the development of emphysema.

\section{APOPTOSIS AND APOPTOTIC CELL CLEARANCE IN ANIMAL MODELS OF "EMPHYSEMA"}

In keeping with these hypotheses, genetically altered mice that show defective apoptotic cell clearance from the lung also show

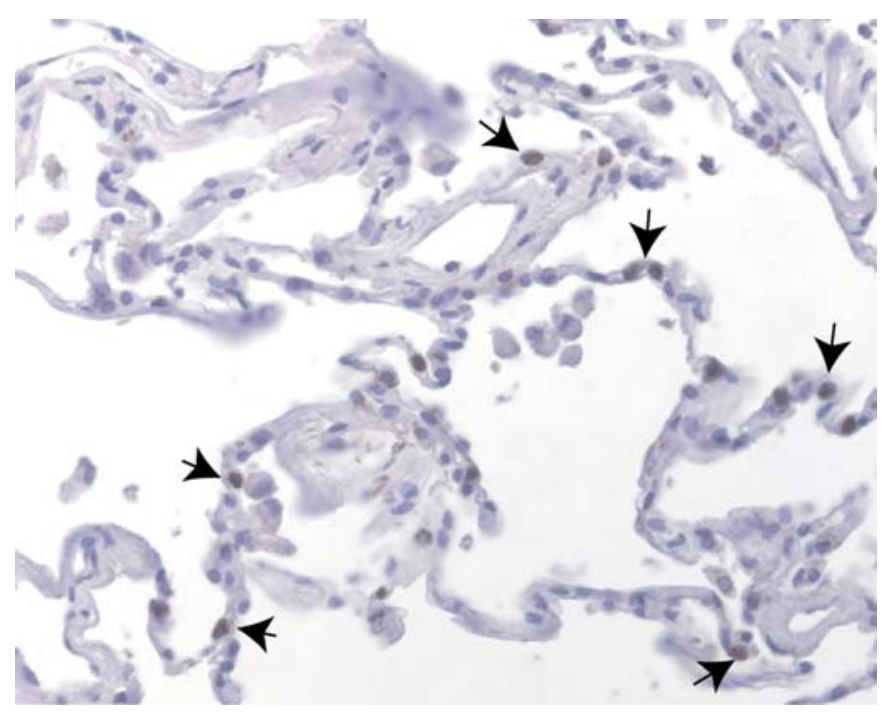

Figure 2. Cell proliferation occurs within the alveolar wall of the human lung. Nondiseased human lungs were obtained from donors rejected for lung transplantation and stained for the presence of the proliferation marker Ki67 (arrows). spontaneous development of alveolar loss. Most striking perhaps are surfactant protein (SP)- $\mathrm{D}^{-1-}$ animals, which are defective in removing apoptotic cells in vitro and in vivo (Figure 3) (15), and which show age-dependent development of "emphysema" as well as of increased matrix metalloproteinase (MMP) activity and oxidant production (16). CD14 ${ }^{-1-}$ (James H. Fisher, personal communication) and mitogen-activated protein kinase kinase (MEKK-1) ${ }^{-1-}$ (unpublished observation) animals also develop alveolar loss, but surprisingly, other efferocytosis-defective mice (including $\mathrm{Mer}^{-1-}$ animals) have not yet been examined for this. Importantly, smoke-exposed mice do exhibit defective apoptotic cell clearance (R.R. Vandivier, unpublished observations). On the other hand, many rodent models of alveolar loss also show detectable apoptotic cells in the lung, including IFN- $\gamma$

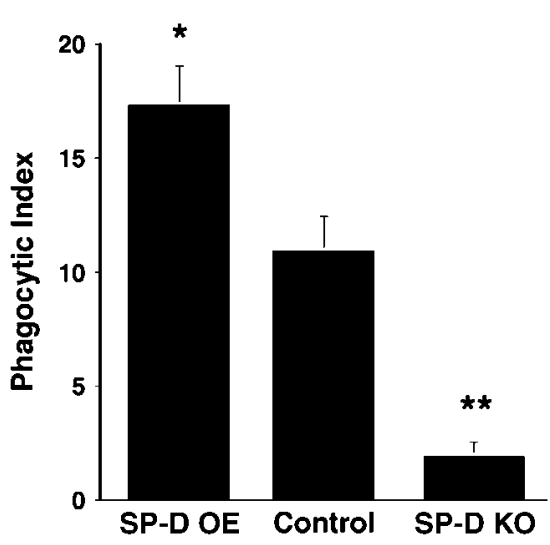

Figure 3. Surfactant protein D (SP-D) regulates removal of apoptotic cells in vivo. Apoptotic human neutrophils were instilled intratracheally into SP-D wild-type, overexpressor (OE), or knockout (KO) mice. Thirty minutes later, lungs were lavaged and alveolar macrophages were assessed for ingestion of apoptotic cells as measured by the phagocytic index. *Significantly different from SP-D KO mice; $p \leqslant 0.05 ;{ }^{* *}$ significantly different from SP-D OE mice; $p \leqslant 0.05$. 
(17) or vascular endothelial growth factor (VEGF) receptor blockade (18), and so forth. Intriguingly, tumor necrosis factor (TNF)- $\alpha$, which is increased in COPD lungs, also itself inhibits apoptotic cell uptake, both in vitro and in vivo (Kathleen A. McPhillips and colleagues and Valeria M. Borges and colleagues, manuscripts in preparation).

\section{APOPTOTIC CELL CLEARANCE IN COPD}

Macrophages lavaged from patients with COPD show evidence of decreased ingested apoptotic cells (8), and have been suggested to exhibit defective phagocytosis of microorganisms (19) or apoptotic $16 \mathrm{HBE}$ cells (20) in vitro. Cigarette smoke inhibits efferocytosis by macrophages in vitro (Reference 21 and our unpublished observations). Of considerable practical and functional importance for this project, macrophages matured from blood monocytes of patients with COPD also showed decreased uptake of Escherichia coli $(22,23)$. These observations support the concept of a defect in efferocytosis (particularly if uptake of unopsonized E. coli is by a similar mechanism as that for apoptotic cells) in patients with COPD, which extends even through cultural maturation of blood monocytes.

There are a significant number of possibilities to explain the defective uptake. A direct action of cigarette smoke on efferocytes is likely but does not easily explain persistent effects after smoking cessation, or action on circulating cells. Increased lung proteolytic activity likely contributes by digesting the surface apoptotic cell recognition receptors, or ligands on apoptotic cells (8). Increased levels of oxidants, or of TNF- $\alpha$ acting to increase intracellular oxidants, also inhibit efferocytosis and, it should be noted, can induce emphysematous changes in mice (24). Newly exposed phosphatidylserine (PS) and calreticulin are key surface ligands on apoptotic cells (11). These are recognized by a variety of receptors and bridge molecules leading to ingestion via two highly conserved and unique signaling pathways $(4,25)$ that converge on the low-molecular-weight $\mathrm{G}$ protein Rac-1. Intriguingly, some of the recognition mechanisms for apoptotic cells are related to innate immune system processes, suggesting that cell deletion and innate immunity may have evolved together from the earliest metazoa. In mammals, this relationship is particularly manifest in the collectin family of innate immune system, pattern recognition, molecules (i.e., SP-A, SP-D, mannose binding lectin [MBL], and the related $\mathrm{C} 1 \mathrm{q}$ ). They recognize and bind to apoptotic as well as necrotic cells and cell debris, and mediate their removal by stimulating lipoprotein receptor-related protein (LRP) on the efferocyte $(15,26,27)$. On the other hand, the lung collectins SP-A and SP-D serve a significant antiinflammatory function in the lung, in part by stimulating the inhibitor membrane signaling molecule signal regulatory protein (SIRP) $\alpha$. We previously showed that SP-A and SP-D globular head groups bind SIRP $\alpha$ and suppress inflammatory mediator release (27). In contrast, in their role as innate immune effectors, SP-A and SP-D globular heads bind foreign organisms or apoptotic cells, which leaves their collagenous tails free to engage LRP on the phagocyte and to induce phagocytosis. Because (1) SP-D has been reported to be decreased in smokers' lungs (28), (2) SP-D marker alleles appear to be predictive of developing COPD (29), and (3) SP-D deletion induces spontaneous "emphysema" in mice (16), lower SP-D levels may contribute to COPD pathogenesis, via defective efferocytosis and releasing normal suppression of inflammation.

In addition, apoptotic cell uptake is significantly regulated by the balance between Rac-1, which is required, and RhoA, which is inhibitory (30-32), and this balance can be seen both in vivo and in vitro, and across different cell types. This raises the intriguing possibility that an intrinsic, or induced, imbalance between these low-molecular-weight GTPases in potential efferocytes may contribute to the impaired clearance, and indeed to the potential for some smokers to develop COPD. By inhibiting 3-hydroxy-3-methylgluatryl coenzyme A (HMG-CoA) reductase, statins limit prenylation of the Rho GTPases, with a preferential effect on RhoA, and in unpublished experiments enhance uptake of apoptotic cells in vitro and in vivo, and in lavaged macrophages from patients with COPD (33). They have also been shown to have suppressive effects in other forms of inflammatory processes, oxidative stress and nuclear factor- $\mathrm{kB}$ activation, and to induce peroxisome proliferator-activated receptors (PPARs) as well as reduce experimental inflammatory lung disease $(34,35)$ and, indeed, cigarette smoke-induced rodent "emphysema" (36). Accordingly, we question whether the possible judicious use of statin therapy might at least improve the removal of apoptotic cells seen in COPD.

\section{CONSEQUENCES OF DEFECTIVE APOPTOTIC CELL RECOGNITION}

Decreased clearance of apoptotic cells by itself is only likely to contribute to COPD via the effects of postapoptotic necrosis, including promotion of inflammation, liberation of intracellular proteases, and possible enhancement of autoimmune responses. This last effect could arise because of autoimmunogens derived from the apoptotic cells if not removed properly, as has been suggested for systemic lupus erythematosis (SLE). However, recognition of apoptotic cells induces a host of additional effects in the normal tissue, each of which, if disrupted in COPD, could contribute to its pathogenesis. In particular, apoptotic cell recognition induces antiinflammatory and antiimmunogenic responses, may stimulate the production of antiproteases, and in particular, may promote cell replacement and tissue repair (Figure 1).

\section{ANTIINFLAMMATORY, ANTIIMMUNOGENIC, AND ANTIPROTEOLYTIC EFFECTS OF APOPTOTIC CELL RECOGNITION}

Defective clearance of apoptotic cells is associated with increased inflammation. In part, this may result from secondary necrosis and release of proteases and other proinflammatory cell contents. However, recognition of apoptotic cells directly induces professional and nonprofessional phagocytes to produce antiinflammatory mediators, such as transforming growth factor (TGF)- $\beta$, interleukin (IL)-10, PPAR $\gamma$, prostaglandin $\mathrm{E}_{2}\left(\mathrm{PGE}_{2}\right)$, and prostaglandin $\mathrm{I}_{2}\left(\mathrm{PGI}_{2}\right)$ (Reference 37 and Celio Freire de Lima and colleagues, manuscript in preparation). As a consequence, apoptotic cell recognition leads to suppression of a wide variety of inflammatory mediators, either spontaneously or after stimulation with, for example, LPS $(37,38)$. This effect can also be shown in vivo wherein the instillation of apoptotic cells into the inflamed murine lung resulted in rapid resolution of the inflammation (39). Direct instillation of PS-containing liposomes into inflamed lungs, to represent the PS that is exposed on apoptotic cells, also suppressed the inflammatory response (39). Furthermore, injection of PS liposomes into an immunization site acts as a striking inhibitor of the adaptive immune response; $\mathrm{T}$ cells, B cells, germinal centers, and antibody production (40) were also shown to be dependent on the local production of active TGF- $\beta$. Defects in these responses would therefore be expected to result in decreased antiinflammatory mediators and increased levels of proinflammatory molecules such as TNF- $\alpha$, IL-1, IL-6, and IL-8. Importantly, apoptotic cell recognition does not alter (or enhance) monocyte chemoattractant protein (MCP)-1 production $(38,39)$; this could act as an additional 
antiinflammatory signal, because recruited monocytes are known to release antiinflammatory mediators, such as IL-10, once they are exposed to apoptotic cells (41).

The pathways leading from recognition of the apoptotic cells to these suppressive responses are not completely clear, although the net effect is that such cells are normally removed silently and without local response. The data to date suggest that the major surface structure on the apoptotic cells that initiates the antiinflammatory responses is the PS, but the receptors on the efferocytes that drive the effect are not fully characterized. A key element to the response is the production, release, and activation of TGF- $\beta$. Because the Rho-family GTPases appear to be involved in its synthesis, this effect may also be susceptible to manipulation by appropriate statin treatment.

Intriguingly, macrophages synthesize and secrete secretary leukocyte protease inhibitor (SLPI) and this is normally increased in response to apoptotic cells (13). Although they do not appear to make significant amounts of $\alpha_{1}$-antiprotease, they can, and do, alter their proportions of tissue inhibitors of matrix metalloproteinases (TIMPs) to MMPs. Accordingly, we hypothesize that another response to apoptotic cells that may be dysregulated in COPD is the production of antiproteases, thereby increasing the protease to antiprotease balance. In keeping with this concept, decreased levels of TIMP are seen in cystic fibrosis (42), together with decreased responses to apoptotic cells (8). Similarly, we are intrigued by the observation that statin treatment can increase the production of TIMPs (9).

\section{APOPTOTIC CELL RECOGNITION INDUCES GROWTH MAINTENANCE FACTORS FOR ALVEOLAR CELLS}

Several lines of evidence lead us to posit a central regulatory role for normal apoptotic cell recognition as the key homeostatic regulator for alveolar-capillary membrane integrity. In this paradigm, continual surveillance and efferocytosis of senescent, apoptotic alveolar epithelial (or endothelial) cells by professional and nonprofessional phagocytes result in synthesis and secretion of growth factors, cytokines, and chemokines that maintain alveolar epithelial and pulmonary vascular integrity. In addition to the other responses, apoptotic cell recognition also results in generation of two key growth factors for alveolar cells: VEGF (43) and hepatocyte growth factor (HGF) (44). VEGF is suggested to be secreted in a paracrine fashion by intact alveolar epithelial cells and phagocytes that recognize apoptotic cells and is proposed to regulate pulmonary endothelial integrity in a VEGF receptor II kinase domain receptor-dependent fashion. TGF- $\beta$ and HGF may regulate epithelial cell proliferation, integrity, and spreading in an autocrine fashion, as well as by controlling matrix integrity, remodeling, and turnover. Impairment in these responses may result in reduced synthesis and secretion of these growth factors, with reduced HGF-mediated filling of epithelial gaps by cell spreading, differentiation, and proliferation. Lower local levels of VEGF, an essential lung homeostatic regulator, would facilitate pulmonary microvascular involution and progressive ischemic involution of the lung septae. In keeping with these suggestions, decreased levels of both of these growth factors have been reported in COPD $(1,45,46)$.

\section{POSSIBILITIES}

One of the key, and so far unanswered, questions raised by these speculations is how many of these defects can be blocked or even reversed, and what effect would that have on the human disease? Emphysematous changes in mice can be induced by dietary restriction and then reversed by restoration of normal nutrition (47). It is also noteworthy that a variety of manipula- tions in mice $(18,48)$ can produce very rapid loss of alveolar structures ("emphysema"), raising the possibility of equally rapid "repair." How these rodent model systems (which are often carried out in relatively young animals) relate to COPD in humans (which is usually a process seen in older subjects and that takes much longer to develop) still needs to be sorted out. On the more positive side, if emphysema develops in part as a response to dysregulation of alveolar cell homeostasis, then effective restoration of the homeostatic processes may, at the minimum, halt progression of the disease, even if it does not actually restore normal lung structure.

Conflict of Interest Statement: P.M.H. does not have a financial relationship with a commercial entity that has an interest in the subject of this manuscript. G.P.C. does not have a financial relationship with a commercial entity that has an interest in the subject of this manuscript. R.W.V. is the recipient of a Pfizer Atorvastatin Research Award totaling $\$ 100,000$. He also is the recipient of a grant from GlaxoSmithKline totaling $\$ 200,000$.

Acknowledgment: The authors express their sincere appreciation for the considerable effort extended by Jeanne Cleary in the planning and execution of the Aspen Lung Conference, and in the manuscript preparation that followed.

\section{References}

1. Kasahara Y, Tuder RM, Cool CD, et al. Endothelial cell death and decreased expression of vascular endothelial growth factor and vascular endothelial growth factor receptor 2 in emphysema. Am J Respir Crit Care Med 2001;163:737-744.

2. Yokohori N, Aoshiba K, Nagai A. Increased levels of cell death and proliferation in alveolar wall cells in patients with pulmonary emphysema. Chest 2004;125:626-632.

3. Imai K, Mercer BA, Schulman LL, et al. Correlation of lung surface area to apoptosis and proliferation in human emphysema. Eur Respir J 2005; 25:250-258.

4. Henson PM, Bratton DL, Fadok VA. Apoptotic cell removal. Curr Biol 2001;11:R795-R805.

5. Tuder RM, Petrache I, Elias JA, et al. Apoptosis and emphysema: the missing link. Am J Respir Cell Mol Biol 2003;28:551-554.

6. Scott RS, McMahon EJ, Pop SM, et al. Phagocytosis and clearance of apoptotic cells is mediated by MER. Nature 2001;411:207-211.

7. Droemann D, Aries SP, Hansen F, et al. Decreased apoptosis and increased activation of alveolar neutrophils in bacterial pneumonia. Chest 2000;117:1679-1684.

8. Vandivier RW, Fadok VA, Hoffmann PR, et al. Elastase-mediated phosphatidylserine receptor cleavage impairs apoptotic cell clearance in cystic fibrosis and bronchiectasis. J Clin Invest 2002;109:661-670.

9. Crisby M, Nordin-Fredriksson G, Shah PK, et al. Pravastatin treatment increases collagen content and decreases lipid content, inflammation, metalloproteinases, and cell death in human carotid plaques: implications for plaque stabilization. Circulation 2001;103:926-933.

10. deCathelineau AM, Henson PM. The final step in programmed cell death: phagocytes carry apoptotic cells to the grave. Essays Biochem 2003;39:105-117.

11. Gardai SJ, McPhillips KA, Frasch C, et al. Cell surface calreticulin initiates clearance of viable or apoptotic cells through trans activation of LRP on the phagocyte. Cell 2005;123:321-334.

12. Spalding KL, Bhardwaj RD, Buchholz BA, et al. Retrospective birth dating of cells in humans. Cell 2005;122:133-143.

13. Odaka C, Mizuochi T, Yang J, et al. Murine macrophages produce secretory leukocyte protease inhibitor during clearance of apoptotic cells: implications for resolution of the inflammatory response. J Immunol 2003; 171:1507-1514.

14. Turato G, Di Stefano A, Maestrelli P, et al. Effect of smoking cessation on airway inflammation in chronic bronchitis. Am J Respir Crit Care Med 1995;152:1262-1267.

15. Vandivier RW, Ogden CA, Fadok VA, et al. Role of surfactant proteins $\mathrm{A}, \mathrm{D}$, and $\mathrm{C} 1 \mathrm{q}$ in the clearance of apoptotic cells in vivo and in vitro: calreticulin and CD91 as a common collectin receptor complex. $J$ Immunol 2002;169:3978-3986.

16. Wert SE, Yoshida M, LeVine AM, et al. Increased metalloproteinase activity, oxidant production, and emphysema in surfactant protein D gene-inactivated mice. Proc Natl Acad Sci USA 2000;97:5972-5977.

17. Wang Z, Zheng $\mathrm{T}$, Zhu Z, et al. Interferon gamma induction of pulmonary emphysema in the adult murine lung. J Exp Med 2000;192:1587-1600.

18. Kasahara Y, Tuder RM, Taraseviciene-Stewart L, et al. Inhibition 
of VEGF receptors causes lung cell apoptosis and emphysema. $J$ Clin Invest 2000;106:1311-1319.

19. Ferrara F, D'Adda D, Falchi M, et al. The macrophagic activity of patients affected by pneumonia or chronic obstructive pulmonary disease. Int J Tissue React 1996;18:109-114.

20. Hodge S, Hodge G, Scicchitano R, et al. Alveolar macrophages from subjects with chronic obstructive pulmonary disease are deficient in their ability to phagocytose apoptotic airway epithelial cells. Immunol Cell Biol 2003;81:289-296.

21. Kirkham PA, Spooner G, Rahman I, et al. Macrophage phagocytosis of apoptotic neutrophils is compromised by matrix proteins modified by cigarette smoke and lipid peroxidation products. Biochem Biophys Res Commun 2004;318:32-37.

22. Prieto A, Reyes E, Bernstein ED, et al. Defective natural killer and phagocytic activities in chronic obstructive pulmonary disease are restored by glycophosphopeptical (inmunoferon). Am J Respir Crit Care Med 2001;163:1578-1583.

23. Finney-Hayward TK, Russell REK, Kon OM, Fitzgerald MF, Barnes PJ, Donnelly LE. Decreased phagocytotic activity of monocyte-derived macrophages in patients with COPD [abstract]. Proc Am Thorac Soc 2005;2:A17.

24. Fujita M, Shannon JM, Irvin CG, et al. Overexpression of tumor necrosis factor-alpha produces an increase in lung volumes and pulmonary hypertension. Am J Physiol Lung Cell Mol Physiol 2001;280:L39-L49.

25. Kinchen JM, Cabello J, Klingele D, et al. Two pathways converge at CED-10 to mediate actin rearrangement and corpse removal in C. elegans. Nature 2005;434:93-99.

26. Ogden CA, deCathelineau A, Hoffmann PR, et al. C1q and mannose binding lectin engagement of cell surface calreticulin and CD91 initiates macropinocytosis and uptake of apoptotic cells. J Exp Med 2001; 194:781-795.

27. Gardai SJ, Xiao YQ, Dickinson M, et al. By binding SIRPalpha or calreticulin/CD91, lung collectins act as dual function surveillance molecules to suppress or enhance inflammation. Cell 2003;115:13-23.

28. Honda Y, Takahashi H, Kuroki Y, et al. Decreased contents of surfactant proteins A and D in BAL fluids of healthy smokers. Chest 1996;109: 1006-1009.

29. Guo X, Lin HM, Lin Z, et al. Surfactant protein gene A, B, and D marker alleles in chronic obstructive pulmonary disease of a Mexican population. Eur Respir J 2001;18:482-490.

30. Hoffmann PR, deCathelineau AM, Ogden CA, et al. Phosphatidylserine (PS) induces PS receptor-mediated macropinocytosis and promotes clearance of apoptotic cells. J Cell Biol 2001;155:649-659.

31. Leverrier Y, Ridley AJ. Requirement for Rho GTPases and PI 3-kinases during apoptotic cell phagocytosis by macrophages. Curr Biol 2001;11: 195-199.

32. Tosello-Trampont AC, Nakada-Tsukui K, Ravichandran KS. Engulfment of apoptotic cells is negatively regulated by Rho-mediated signaling. J Biol Chem 2003;278:11772-11779.

33. Morimoto K, Janssen WJ, Fessler MB, McPhillips KA, Borges VM, Bowler RP, Xiao YQ, Kench JA, Henson PM, Vandivier RW. Lovastatin enhances clearance of apoptotic cells (efferocytosis) with implications for chronic obstructive pulmonary disease. J Immunol 2006; 176:7657-7665.

34. Jacobson JR, Barnard JW, Grigoryev DN, et al. Simvastatin attenuates vascular leak and inflammation in murine inflammatory lung injury. Am J Physiol Lung Cell Mol Physiol 2005;288:L1026-L1032.

35. Fessler MB, Young SK, Jeyaseelan S, et al. A role for hydroxy-methylglutaryl coenzyme a reductase in pulmonary inflammation and host defense. Am J Respir Crit Care Med 2005;171:606-615.

36. Lee JH, Lee DS, Kim EK, et al. Simvastatin inhibits cigarette smokinginduced emphysema and pulmonary hypertension in rat lungs. Am J Respir Crit Care Med 2005;172:987-993.

37. Fadok VA, Bratton DL, Konowal A, et al. Macrophages that have ingested apoptotic cells in vitro inhibit proinflammatory cytokine production through autocrine/paracrine mechanisms involving TGF-beta, PGE2, and PAF. J Clin Invest 1998;101:890-898.

38. McDonald PP, Fadok VA, Bratton D, et al. Transcriptional and translational regulation of inflammatory mediator production by endogenous TGF-beta in macrophages that have ingested apoptotic cells. J Immunol 1999;163:6164-6172.

39. Huynh ML, Fadok VA, Henson PM. Phosphatidylserine-dependent ingestion of apoptotic cells promotes TGF-beta1 secretion and the resolution of inflammation. J Clin Invest 2002;109:41-50.

40. Hoffmann PR, Kench JA, Vondracek A, et al. Interaction between phosphatidylserine and the phosphatidylserine receptor inhibits immune responses in vivo. J Immunol 2005;174:1393-1404.
41. Voll RE, Herrmann M, Roth EA, et al. Immunosuppressive effects of apoptotic cells. Nature 1997;390:350-351.

42. Delacourt C, Le Bourgeois M, D'Ortho MP, et al. Imbalance between $95 \mathrm{kDa}$ type IV collagenase and tissue inhibitor of metalloproteinases in sputum of patients with cystic fibrosis. Am J Respir Crit Care Med 1995; 152:765-774

43. Golpon HA, Fadok VA, Taraseviciene-Stewart L, et al. Life after corpse engulfment: phagocytosis of apoptotic cells leads to VEGF secretion and cell growth. FASEB J 2004:18:1716-1718.

44. Morimoto K, Amano H, Sonoda F, et al. Alveolar macrophages that phagocytose apoptotic neutrophils produce hepatocyte growth factor during bacterial pneumonia in mice. Am J Respir Cell Mol Biol 2001; 24:608-615.

45. Kanazawa H, Hirata K, Yoshikawa J. Imbalance between vascular endothelial growth factor and endostatin in emphysema. Eur Respir J 2003; 22:609-612.

46. Plantier L, Marchand-Adam S, Marchal-Somme J, et al. Defect of hepatocyte growth factor production by fibroblasts in human pulmonary emphysema. Am J Physiol Lung Cell Mol Physiol 2005;288:L641-L647.

47. Massaro D, Massaro GD, Baras A, et al. Calorie-related rapid onset of alveolar loss, regeneration, and changes in mouse lung gene expression. Am J Physiol Lung Cell Mol Physiol 2004;286:L896-L906.

48. Aoshiba K, Nagai A. Differences in airway remodeling between asthma and chronic obstructive pulmonary disease. Clin Rev Allergy Immunol 2004;27:35-43.

\section{Statins Enhance Clearance of Apoptotic Cells through Modulation of Rho-GTPases}

Konosuke Morimoto, William J. Janssen, Michael B. Fessler, Yi Qun Xiao, Kathleen A. McPhillips, Valeria M. Borges, Jennifer A. Kench, Peter M. Henson, and R. William Vandivier

Division of Pulmonary Sciences and Critical Care Medicine, University of Colorado Health Sciences Center; and Department of Immunology, National Jewish Medical and Research Center, Denver, Colorado

Clearance of apoptotic cells (efferocytosis) is a key modulator of the inflammatory response, and is dysregulated in several chronic inflammatory lung diseases, including chronic obstructive pulmonary disease and cystic fibrosis. Rho-GTPases are signaling molecules that differentially regulate efferocytosis: RhoA and its downstream effector Rho kinase inhibit efferocytosis, whereas Rac-1/Cdc42 stimulate it. Statins are 3-hydroxyl-3methylglutaryl coenzyme A (HMG-CoA) reductase inhibitors with broad antiinflammatory effects, largely based on their ability to block prenylation and membrane localization of RhoGTPases, including RhoA. Therefore, we hypothesized that statins would enhance efferocytosis by inhibiting RhoA. In vitro, lovastatin increased efferocytosis by both human and murine macrophages. The positive effect of lovastatin on efferocytosis was prevented by mevalonate, farnesylpyrophosphate, and geranylgeranylpyrophosphate, and was mimicked by specific inhibitors of farnesyltransferase and geranylgeranyltransferase. These results suggested that lovastatin acted by inhibiting HMG-CoA reductase and subsequent downstream prenylation events. In support of this notion, lovastatin decreased membrane localization of RhoA, but had no effect on expression of macrophage efferocytosis receptors. To determine whether lovastatin enhanced efferocytosis in vivo, mice were challenged intratracheally with apoptotic thymocytes, in the presence and absence of lovastatin or the Rho kinase inhibitor (Y-27632), and clearance of these apoptotic thymocytes was assessed. Both lovastatin and Y-27632 enhanced efferocytosis in vivo. These findings suggest that statins enhance efferocytosis in vitro and in vivo, and may ultimately play 